\title{
Effects of physical activity to cardiorespiratory changes
}

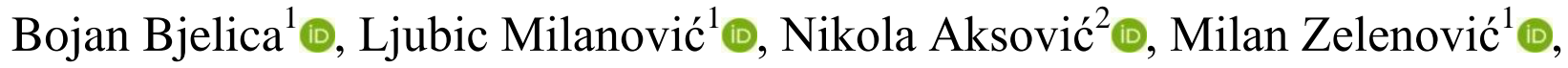 \\ Danijel Božić ${ }^{1}$ (D)
}

${ }^{1}$ Faculty of Physical Education and Sport, University of East Sarajevo, Bosnia and Herzegovina. ${ }^{2}$ Faculty of Sport and Physical Education, University of Niš, Serbia.

\begin{abstract}
Cardiorespiratory endurance is associated with the development of cardiovascular and respiratory systems' ability to maintain and deliver oxygen to the engaged muscles during long-term physical activity, as well as the muscle ability to obtain required energy through aerobic processes. Physical activities of aerobic character give best results when performed 3-5 times a week. Training duration should be within 50-60 minutes. This way of exercising will surely lead to positive cardiorespiratory changes in both males and females. This paper uses introspection method to review relevant scientific literature concerning our topic of interest. We emphasize that physical activity has a significant influence on cardiorespiratory abilities, that is, it increases maximum oxygen uptake and personal fitness index, both of which are associated with the increased cardiorespiratory ability. Arterial blood pressure is significantly corrected; however, it is necessary to start engaging in physical activities on time for prevention purposes. Due to greater body engagement, physical activities represent one puzzle piece of crucial importance in maintaining cardiorespiratory health.
\end{abstract}

Keywords. Blood pressure, HR, intensity, $\mathrm{VO}_{2}$ max.

\section{Introduction}

Physical activity (PA) is defined as any kind of physical movement generated by the skeletal muscles, and for which energy expenditure is required (WHO, 2019). Such physical movements cause a noticeable change in cardiovascular function and show a great potential in prevention and rehabilitation of cardiovascular diseases, which can gravely affect the quality of life (WHO, 2019; Jakovljevic, 2018). Beneficial effects of physical exercise on cardiovascular diseases can be seen in: the improvement of aerobic capacities and metabolic functions, the amplification of the lipid profile, insulin sensitivity of the immune system, the increase of myocardial perfusion and fibrinolytic activity, the decrease of thrombocyte adherence due to increased prostaglandin PGI2 synthesis, the increase in energy consumption (important for maintaining ideal body mass), prevention and treatment of diabetes, and stress control (Bidde et al., 1999). Epidemiological studies have found a positive association between the increased energy consumption caused by physical activity and the reduction in lipid parameters and body mass when combined with dieting and physical exercise (BaxterJones \& Maffulli, 2003). Physical activity, by altering chemistry and lipoprotein metabolism, slows down the degree of atherosclerosis in coronary arteries in individuals who exercise regularly (Clark et al., 2005). When it comes to prevention and reduction of cardiovascular risk, aerobic physical exercises (jogging, swimming, riding a bike) by the intensity of the medium load training ( $65 \%$ of mean respiratory volume) have a positive effect. The best kind of physical 
activity is the one where endurance and strength are in the focus (Hu et al., 2000). While having a positive effect on body composition, physical activity also positively influences the reduction in fat deposits and maintains healthy body mass (Blair et al., 2004; Haskell et al., 2007; Garber et al., 2011; Golubic et al., 2012; Can et al., 2014; Rosa et al., 2014; Clark, 2015; Liu et al., 2018; Can et al., 2019). Regular PA lead to not only increased aerobic, but also anaerobic parameters (Pilch et al., 2017), decreases the negative effects of diabetes in diabetic patients (Lynch et al., 1996; Gregg et al., 2003), helps those with cardiovascular disorders (Ewing, 2011; Nystoriak \& Bhatnagar, 2018; Matthew \& Aruni, 2018; Pinckard et al., 2019), increases bone density and reduces osteoporotic changes (Warburton et al., 2001; Carter \& Hinton, 2014).

Cardiorespiratory endurance or aerobic endurance is whole body's capability to maintain long-term physical activity and it involves relatively large muscle groups (Petrovic-Oggiano et al., 2010). Cardiorespiratory endurance is closely tied with the development of cardiovascular and respiratory ability to maintain oxygen delivery to the muscles engaged in long-term physical activity, as well as with the muscle ability to acquire needed energy through aerobic processes. A lot of scientist who study PA take maximal oxygen uptake ( $\left.\mathrm{VO}_{2} \mathrm{max}\right)$, also known as maximal aerobic power or maximal aerobic capacity, as the most objective laboratory parameter for cardiorespiratory endurance (Gianuzzi et al., 2003). Maximal oxygen uptake $\mathrm{VO}_{2}$ max refers to the highest amount of oxygen an individual can use or spend during one minute of maximum intensity loading. $\mathrm{VO}_{2} \max$ values can be directly measured or estimated based on technical characteristics of the used equipment, test protocol, and time and load duration (Armstrong, Welsman, \&, Winsley, 1996). When estimating maximum oxygen uptake, where the test ends at submaximal load level with extrapolation of the results to the maximum values, the term highest value or peak oxygen uptake ( $\mathrm{VO}_{2}$ peak). To obtain this
$\mathrm{VO}_{2}$ peak value, through the process of progressive overload, it is required to achieve the intensity which allows for minimal duration of 3-5 minutes, when oxygen uptake would reach its plateau. The endurance training can deliver and uptake more oxygen in active muscles. That improvement allows individuals to do a physical activity for which higher intensity endurance is needed, while also improving the physical ability.

Based on physical review, it is recommended that aerobic activities should last 12-16 weeks, 3-5 times a week. Training duration should be approximately 50-60 minutes. This principle greatly influences cardiorespiratory changes in both male and female test subjects. This kind of physical training gives considerably better results that the trainings that last 20-40 minutes (Hsiao et al., 1998; Amiril et al., 2013).

\section{The effects of physical activity on arterial blood pressure}

Exercise is the key therapeutic component for early prevention and treatment of hypertension. Multiple studies have shown how exercise benefits hypertension by reducing systolic and diastolic blood pressure for at least $5-7 \mathrm{mmHg}$ in hypertension patients (Diaz \& Shimbo, 2013; Pescatello et al., 2004; Carlson et al., 2014). Environment factors, including sedentary lifestyle, have been the most prominent as risk factors for hypertension development. While standard antihypertensive therapy exists, physical exercise should also be included due to its positive impact on hypertension and cardiovascular disease prevention (Diaz \& Shimbo, 2013; Rossi et al., 2012). Based on this, changing one's lifestyle and being physically active are two very important components of both the European and American World Health Organization guidelines on antihypertensive treatment (James et al., 2014; Mendis, 2014). Differences in workout regime, environment as well as genetic factors can account for major differences and variabilities in blood pressure in response to exercise among different studies 
(Members, 2013; Ash et al., 2013). In one study, $20-25 \%$ of individuals diagnosed with hypertension did not have a positive reaction and their exercise did not result in blood pressure reduction (Pescatello et al., 2008). Other studies show that blood pressure can be reduced through exercise (Chobanian et al., 2003; Pontes et al., 2008). However, studies that look into blood pressure reduction, as a consequence of chronic exercise, can neglect the acute results after the exercise, and what can be lost in time (Cornelissen \& Fagard, 2005). Although the mean value of systolic and diastolic pressure during $24 \mathrm{~h}$ period is approximately $3.2 \mathrm{mmHg}$ and $1.8 \mathrm{mmHg}$ respectively, the reduction is greater during first couple of hours after the exercise, to such extent that even some participants diagnosed with hypertension reach normal blood pressure values (Pescatello \& Kulikowich, 2001). Previous studies show that aerobic program increases $\mathrm{VO}_{2}$ max, however, it is more important to note that it reduces both heart rate and blood pressure (Astorino et al., 2012). To conclude, irrespective of exercise characteristics, or load intensity, blood pressure is most commonly corrected after acute exercise. If you become physically active, you can reduce your systolic blood pressure - the largest number in blood pressure reading - on average $4-9 \mathrm{mmHg}$, which is as good as certain antihypertensive medications.

In order to reduce the need for antihypertensive medication, some people only need to introduce regular exercise in their daily routine (Flint, 2019). The deparment for health and social services recommends at least 150 minutes of medium intensity aerobic activity or 75 minutes of high intensity aerobic activity per week or a combination of the two. It is also recommended to include at least 30 minutes of aerobic activity on a daily basis during the week. If this is not possible to implement in one's schedule, the workout plan can be broken down into smaller units as these can be extremely useful. Training could be divided into three 10-minutes long aerobic exercise sessions and have the same advantages as one 30-minute long session (Bhatt, 2016; Beddhu et al., 2018).

\section{The effects of physical activity on $\mathrm{VO}_{2}$ max increase}

The benefits of PA are countless, but here we will point out the improvements in aerobic state of the organism (Myers et al., 2002; McGinnis \& Foege, 1993). Donnelly et al. (2009) assert that load intensity during workout needs to be at least $50 \%$ of maximum heart rate and to have a corresponding duration, so it could result in beneficial changes with maximum oxygen uptake, The degree of cardiorespiratory ability varies depending on the overall state of respiratory, cardiovascular and musculoskeletal systems, and its estimate is important as it is connected to the overall health status of an individual. Multiple studies show that recreational workout and continuous exercise plans can significantly improve cardiovascular system (Kostić \& Zagorc, 2005; Basset \& Howley, 2000). Some studies show that programs of aerobic character can influence the cardiorespiratory fitness by enhancing the degree of respiratory abilities (Wilmore \& Costill, 1999; Pantelić et al., 2007; Grant et al., 2002; Kingwell \& Jennings; 1993; Kostić \& Zagorc, 2005; Thomsen \& Ballor,1991). Bad cardiorespiratory ability increases the degree of many risk factors and can cause premature death. Improving cardiorespiratory abilities is associated with a lower chance of premature death (Kalyani et al., 2007; Myers et al., 2002). Physical fitness is a measure of cardiorespiratory, endocrine and metabolic functions (Castillo-Garzón et al., 2006).

With age, $\mathrm{VO}_{2}$ max is decreased by nearly $10 \%$ between 25 and 30 years of age in adults of both sexes, irrespective of activity levels (Bortz \& Bortz, 1996; Citation et al., 2016; Eskurza et al., 2002; Fitzgerald et al., 1997; Heath et al., 1981; Degens et al., 2013; Pimentel et al., 2003). On average, men have a higher $\mathrm{VO}_{2}$ max than women, which comes as a consequence of greater ventricle push, exit volume, 
hemoglobin concentration, muscle mass composition and lower body fat (Cheuvront et al., 2003). The main function of the cardiovascular and respiratory systems is to supply enough oxygen and nutrition to the body, release the $\mathrm{CO}_{2}$ and regulate metabolism (Wilmore \& Costill, 2005). PA influences health improvement, improves the cardiorespiratory condition, body composition and also benefits psychosocial being. Besides, PA is an important segment in prevention and treatment of diabetes (Kelley \& Kelley, 2013; Bae et al., 2015; Yong et al., 2014; Lee et al., 2015; Boström et al., 2012; Alberga et al., 2011). Previous studies researched $\mathrm{VO}_{2}$ max changes after interventions with certain experimental treatment of aerobic characteristics at a given time span (Shim et al., 2010; Askarabadi et al., 2012; Rezaimanesh \& Amiri-Farsani, 2011; Osei-Tutu \& Campagna, 2005). Some studies even compared a few aerobic programs of different load intensity, continuous aerobic exercise controlled for total scope of activities and energy consumption during workout. Research shows that aerobic capacity is significantly higher in groups that experienced higher intensity load (Braith et al., 1994; Burke \& Franks, 1975; Crouse et al., 1997; Duncan et al., 1991; Gossard et al., 1986; Gutin et al., 2002; Kang et al., 2002; O'Donovan et al., 2005; Savage et al., 1986).

Endurance training with the intensity of $60 \%$ $\mathrm{VO}_{2}$ max is equally as efficient, or even more, as the intensity of $70 \% \quad \mathrm{VO}_{2} \max$ for the improvement of aerobic fitness in older population. In other words, healthy seniors, adults with sedentary lifestyle can see a major improvement in their aerobic fitness through aerobic exercise with the intensity of approximately 60\% $\mathrm{VO}_{2}$ max (Huang et al., 2005). Unfortunately, these studies did not adequatelly discuss the relationship between intensity and load dosage with exerciseinduced $\mathrm{VO}_{2} \max$ increase. Although many studies have tried to explain the relationship between high and low intensity exercise intensity to improve $\mathrm{VO}_{2}$ max, it remains unclear whether there is an optimal intensity training for $\mathrm{VO}_{2}$ max increase (Daussin et al., 2008). Finding this relationship represents the critical unknown link and an adequate explanation on $\mathrm{VO}_{2}$ max increase (Gormley et al., 2008).

\section{The effects of physical activity on heart rate}

The effects of physical exercise on human body has been a major research interest in the last couple of decades (Nottin et al., 2002; Ekblom et al., 1986), and many have been identified as a response to eg. higher cardiac work in the beginning of workout or training adjustments. According to the American Heart Association (AHA) normal resting heart rate for adults should be $60-100$ beats per minute. Tachycardia is high resting heart rate, defined as higher than 100 beats per minute. Bradycardia is low resting heart rate, defined as lower than 60 beats per minute. During sleep, reduced heart rate of approximately $40-50$ beats per minute are considered normal. If heart is not pumping at a consistent rate, it is called arrythmia. Heart rate abnormalities can be an important indicator of the presence of a disease (American Heart Association, 2017), which is why regular exercise comes as highly recommended. Based on AHA recommendations, physical activity and exercise should be conducted regularly, preferably every day of the week for at least 30 minutes with medium to high intensity, based on individual's physical ability (Pearson et al., 2002). One of the possible explanations as to why regular PA and exercise increase lifespan, could be the mediating effect of resting heart rate. Regular PA decreases resting heart rate

Huang et al. (2005), Zheng et al. (2015), Cramer et al. (2014); lower resting heart rate seems to be inversely proportional with the expected lifespan (Hartaigh et al., 2014) and is positively correlated to the cardiovascular system (Aune et al., 2017). Aerobic activities are recommended as the best option. The most common exercises are: jogging, swimming, bicycling, climbing, walking, and many other sports that require increased work of the 
cardiovascular and respiratory systems. The effects of correctly dosed exercise are the improvements in general body fitness and increased endurance (Kuper, 1971). Decreased resting heart rate is common among sportsmen (Boutcher et al., 1998; Shin et al., 1997).

Aerobic exercise can lead to increased heart rate in individuals who had previously led sedentary lifestyle (Schuit et al., 1999; Levy et al., 1998). Hagginbotham et al. (1986) have shown that men are more likely to have lower HA than women, when doing identical intensity exercise. Furthermore, Rennie et al. (2003) showed that increased rate of medium intensity PA significantly lowered men's resting heart rate, but the same effect was not found in women. Low heart rate, at least partially, is a result of increased parasympathetic tonus and can be linked with PA-induced improvements in sympathetic control of the vasomotor tonus (Shin et al., 1997; Yataco et al., 1997). However, others note that parasympathetic tonus can increase high intensity activity, eg. jogging, but not medium intensity activity (Schuit et al., 1999). In the begining of exercise, heart rate increases due to the inhibition of vagus activity, which not only increases the atrium contractility, but also the transmission speed of ventricle depolarization wave (Clausen, 1977), unrelated to the level of activity's intensity (Baum et al., 1992; Araújo, 1985) or aerobic abilities of healthy individuals (Araújo et al., 1989; Borst et al., 1982). Under the influence of PA, heart rate slows down.

\section{Conclusion}

Physical activity represents a very important segment in protection and improvement of our health. Research shows that regular PA provides multiple health benefits and reduces mortality related to any cause. Based on numerous research and reviews, we can conclude that: PA has a major impact on cardiorespiratory abilities, it increases maximum oxygen uptake and personal fitness index. Arterial blood pressure is significantly improved however, it is advisable to start exercising on time for the sake of early prevention. Due to increased body engagement, PA works to decrease heart rate and optimize cardiac work. Physical activity represents an important segment in the overall improvement of cardiorespiratory functions.

\section{Acknowledgment}

The authors would like to thank every participant for his effort and time.

\section{Funding}

No external funding was received for this study.

\section{Declaration of interest}

The authors report no conflict of interest.

\section{References}

Alberga, A.S., Sigal, R.J., \& Kenny, G.P. (2011). A review of resistance exercise training in obese adolescents. Phys Sportsmed, 39 (2), 50-63.

American Heart Association. (2017). All About Heart Rate (Pulse).

Amiri, H., Mirzaie, B., \& Elmieh, A. (2013). Effect of low and high intensity walking programs on body composition of overweight women. Euro J Exp Bio, 3(5), 282-286.

Araújo, C.G.S. (1985). Fast "on" and "off" heart rate transients at different bicycle exercise levels. Int $J$ Sports Med, 6(2), 68-73.

Araújo, C.G.S., Nóbrega, A.C., \& Castro, C.L. (1989). Vagal activity: effect of age, sex and physical pattern. Braz J Med Biol Res, 22(7), 909-911.

Armstrong, N., \& Welsman, J.R. (1994). Assessment and interpretation of aerobic fitness in children and adolescents. Exerc Sport Sci Rev, 22, 435-476.

Armstrong, N., Welsman, J. \&, Winsley, R. (1996). Is peak $\mathrm{VO}_{2}$ a maximal index of children's aerobic fitness? Int J Sports Med, 17, 356-359.

Armstrong, N., Welsman, J.R., \& Chia, M.Y.H. (2001). Short term power output in relation to growth and maturation. Br J Sports Med, 35, 118124. 
Ash, G.I., Eicher, J.D., \& Pescatello, L.S. (2013). The promises and challenges of the use of genomics in the prescription of exercise for hypertension: the 2013 update. Curr Hypertens Rev, 9 (2), 130147.

Askarabadi, S.H., Valizadeh, R., \& Daraei, F. (2012). The effects of aerobic exercise on some pulmonary indexes, body composition, body fat distribution and $\mathrm{VO}_{2}$ max in normal and fat men of personal and members of faculty of Azad university Bebahan branch. Procedia Soc Behav Sci, 46, 3041-3045.

Astorino, T.A., Allen, R.P., Roberson, D.W., \& Jurancich, M. (2012). Effect of high-intensity interval training on cardiovascular function, $\mathrm{VO}_{2}$ max, and Muscular Force. J Strength Cond Res, 26(1), 138-145.

Aune, D., Sen, A., o'Hartaigh, B., Janszky, I., Romundstad, P.R., Tonstad S., \& Vatten, L.J. (2017). Resting heart rate and the risk of cardiovascular disease, total cancer, and allcause mortality- a systematic review and doseresponse meta-analysis of prospective studies. Nutr Metab Cardiovasc Dis, 27(6), 504-517.

Bae, J.Y., Jang, K.S., Kang, S., Han, D.H., Yang, W., \& Shin, K.O. (2015). Correlation between basic physical fitness and pulmonary function in Korean children and adolescents: a crosssectional survey. J Phys Ther Sci, 27 (9), 26872692.

Bailey, R.C., Olson, J., Pepper, S.L., Porszasz, J., Barstow, T.J., \& Cooper, D.M. (1995). The level and tempo of children's physical activities: an observational study. Med Sci Sports Exerc, 27, 1033-1041.

Basset, D.R. Jr., \& Howley, E.T. (2000). Limiting factors for maximum oxygen uptake and determinants of endurance performance. Med Sci Sports Exerc, 32(1), 70.

Baum, K., Essfeld, D., Leyk, D., \& Stegemann J. (1992). Blood pressure and heart rate during restexercise and exercise-rest transitions. Eur J Appl Physiol Occup Physiol, 64 (2), 134-138.

Baxter-Jones, A. \& Maffulli, N. (2003). Endurance in young athletes: it can be trained. Br J Sports Med, 37, 96-99.
Baxter-Jones, A., Goldstein, H., \& Helms, P.J. (1993). The development of aerobic power in young athletes. J Appl Physiol, 75, 1160-1167.

Beddhu, S., Chertow, G.M., Cheung, A.K., Cushman, W.C., Rahman, M., Greene, T., Wei, G., Campbell, R.C., Conroy, M., Kitzman, D., Lash, J., Papademetriou, V., Pisoni, R., Riessen, E., Rosendorff, C., Watnick, S.G., Whittle, J., \& Whelton, P.K. (2018). Influence of baseline diastolic blood pressure on effects of intensive compared with standard blood pressure control. Circulation, 137(2), 134-143.

Bhatt, D.L. (2016). Troponin and the J-curve of diastolic blood pressure: when lower is not better. J Am Coll Cardiol, 68, 1723-1726.

Bidde, S., Sallis, J.F. \& Cavill, N. (1999). Young and active? Young people and health enhancing physical activity-evidence and implications. London: Health Education Authority.

Blair, S.N., LaMonte, M.J., \& Nichaman, M.Z. (2004). The evolution of physical activity recommendations: how much is enough? Am J Clin Nutr, 79(5), 913-920.

Borst, C., Wieling, W., van Brederode, J.F., Hond, A., de Rijk, L.G. \& Dunning, A.J. (1982). Mechanisms of initial heart rate response to postural change. Am J Physiol Heart Circ Physiol, 243(5), 676-681.

Bortz, W.M. (1996). How fast do we age? Exercise performance over time as a biomarker. J Gerontol A Biol Sci Med Sci, 51, 223-225.

Boström, P., Wu, J., Jedrychowski M.P., Korde, A., Ye, L., Lo, J.C., Rasbach, K.A., Bostrom, E.A., Choi, Y.H., Long, J.Z., Kajimura, S., Zingaretti, M.C., Vind, B.F., Tu, H., Cinti, S., Hojlund, K., Gygy, S.P., \& Spiegelman, B.M. (2012). A PGC1$\alpha$-dependent myokine that drives brown-fat-like development of white fat and thermogenesis. Nature, 481, 463-468.

Boutcher, S.H., Nugent, FW., McLaren, P.F., \& Weltman, A.L. (1998). Heart period variability of trained and untrained men at rest and during mental challenge. Psychophysiology, 35(1), 16-22.

Braith, R.W., Pollock, M.L., Lowenthal, D.T., Graves, J.E., \& Limacher, M.C. (1994). Moderate- and high-intensity exercise lowers blood pressure in nonrotensive subjects 60 to 79 years of age. Am J Cardiol, 73(15), 1124-1128. 
Burke, E.J. \& Franks, B.D. (1975). Changes in $\mathrm{VO}_{2}$ resulting from bicycle training at different intensities holding total mechanical work constant. Research Quarterly. American Alliance for Health, Physical Education and Recreation, 46 (1), 31-37.

Buskirk, E.R. \& Hodgson, J,L. (1987). Age and aerobic power: the rate of change in men and women. Fed Proc, 46(5), 1824-9.

Can, S., Arslan, E., \& Ersöz, G. (2014). Current perspectives on physical activity. Ankara Üniv Spor Bil Fak, 12(1), 1-10.

Can, S., Demirkan, E., \& Ercan, S. (2019). The effects of exercise preferences on body fat and body mass index by self-report. Universal Journal of Educational Research, 7(1), 293-297.

Carlson, D.J., Dieberg, G., Hess, N.C., Millar, P.J., \& Smart, N.A. (2014). Isometric exercise training for blood pressure management: a systematic review and meta-analysis. Mayo Clinic Proceedings, 89(3), 327-334.

Carter M.I., \& Hinton, P.S. ( 2014). Physical Activity and Bone Health. Missouri Medicine, 111(1), 5964.

Castillo-Garzón, M.J., Ruiz, J.R., Ortega, F.B., \& Gutiérrez, A. (2006). Anti-aging therapy through fitness enhancement. Clin Interv Aging, 1(3), 213220.

Cheuvront, S.N., Carter, R., DeRuisseau, K.C., \& Moffatt, R.J. (2005). Running performance differences between men and women: an update. Sport Med, 35, 1017-1024.

Chobanian, A.V., Bakris, G.L., Black, H.R., Cushman, W.C., Green, L.A., Jr, J.L.I., Jones, D.W., Materson, B.J., Oparil, S., Jr, J.T.W., Roccella, E.J., \& National Hight Blood Pressure Education Program Coordinating Committee. (2003). The Seventh Report of the Joint National Committee on Prevention, Detection, Evaluation, and Treatment of High Blood Pressure: the JNC 7 report. JAMA, 289 (19), 2560-2571.

Citation, K. C.H., Wheatley, C.M., Behnia, M., \& Johnson, B.D. (2016). The effect of aging on relationships between lean body mass and $\mathrm{VO}_{2} \mathrm{max}$ in rowers. PLoS One, 11(8), e0160275.

Clark, J.E. (2015). Diet, exercise or diet with exercise: comparing the effectiveness of treatment options for weight-loss and changes in fitness for adults (18-65 years old). J Diabetes Metab Disord, 14, 73.

Clark, A.M., Hartling, L., \& Vandermeer, B. (2005). Meta-analysis: secondary prevention programs for patients with coronary artery disease. Ann Intern Med, 143(9), 659-672.

Clausen, J.P. (1977). Effect of physical training on cardiovascular adjustments to exercise in man. Physiological Reviews, 57 (4), 779-815.

Cornelissen, V.A. \& Fagard, R.H. (2005). Effect of resistance training on resting blood pressure: a meta-analysis of randomized controlled trials. Journal Hypertens, 23(2), 251-259.

Cramer, H., Lauche, R., Haller, H., Steckhan, N., Michalsen, A., \& Dobos G. (2014). Effects of yoga on cardiovascular disease risk factors: a systematic review and meta-analysis. Int $J$ Cardiol, 173(2), 170-183.

Crouse, S.F., O'Brien, B.C., Grandjean, P.W., Lowe, R.C., Rohach, J.J., Green, J.S. \& Tolson, H. (1997). Training intensity, blood lipids, and apolipoproteins in men with high cholesterol. J Appl Physiol, 82(1), 270-277.

Daussin, F.N., Zoll, J., Dufour, S.P., Ponsot, E., Lonsdorfer, W.E, Doutreleau, S., Mettauer, B., Piquard, E., Geny, B., \& Richard, R. (2008). Effect of interval versus continuous training on cardiorespiratory and mitochondrial functions: relationship to aerobic performance improvements in sedentary subjects. Am J Physiol Regul Integr Comp, 295(1), R264-272.

Degens, H., Maden, W.T.M., Ireland, A., Korhonen, M.T., Suominen, H., Heinonen, A., Radak, Z., McPhee, J.S., \& Rittweger, J. (2013). Relationship between ventilatory function and age in master athletes and a sedentary reference population. Age (Dordrecht, Netherlands), 35(3), 1007-1015.

Diaz, K.M. \& Shimbo, D. (2013). Physical activity and the prevention of hypertension. Curr Hypertens Rep, 15(6), 659-668.

Donelly, J.E., Blair, S.N., Jakicic, J.M., Manore, M.M., Rankin, J.W., \& Smith, B.K. (2009). ACSM Position Stand. Appropriate physical activity intervention strategies for weight loss and prevention of weight regain for adults. Med Sci Sports Exerc, 41(2), 459-471. 
Duncan, J.J., Gordon, N.F., \& Scott, C.B. (1991). Women walking for health and fitness. how much is enough? JAMA, 266, 3295-3299.

Ekblom, B., Astrand, P.O., Saltin, B., Stenberg, J., \& Wallstrom, B. (1986). Effect of training on circulatory response to exercise. J Appl Physiol, 24(4), 518-528.

Eskurza, I., Donato, A.J., Moreau, K.L., Seals, D.R., \& Tanaka, H. (2002). Changes in maximal aerobic capacity with age in endurance-trained women: 7-yr follow-up. J Appl Physiol, 92, 2303-2308.

Ewing, C.G. (2011). Quantity and quality of exercise for developing and maintaining cardiorespiratory, musculoskeletal, and neuromotor fitness in apparently healthy adults: guidance for prescribing exercise. Med Sci Sports Exerc, 43(7), 1334-1359.

Fitzgerald, M.D., Tanaka, H.T.Z., \& Seals, D.R. (1997). Age-related declines in maximal aerobic capacity in regularly exercising vs. sedentary women: a meta-analysis. J Appl Physiol, 83, 160165.

Flint, A.C., Conell, C., Ren, X., Banki, N.M., Sheila, L., Chan, M.D., Vivek, A. Rao, M.D., Ronald, B., Melles, M.D., \& Deepak, L. (2019). Effect of systolic and diastolic blood pressure on cardiovascular outcomes. $N$ Engl J Med, 381(3), 243-251.

Garber, C.E., Blissmer, B., Deschenes, M.R., Franklin, B., Lamonte, M.J., Lee, I.M., Nierman, D.C., \& Swain, D.P. (2011). Quantity and quality of exercise for developing and maintaining cardiorespiratory, musculoskeletal, and neuromotor fitness in apparently healthy adults: guidance for prescribing exercise. Med Sci Sports Exerc, 43(7), 1334-1359.

Giannuzzi, P., Mezzani, A., Saner, H., Björnstad, H., Fioretti, P., Mendes, M., Cohen-Solal, A., Dugmore, L., Hambrecht, R., Hellemans, I., McGee, H., Perk, J., Vanhees, L., Veress, G., \& Working Group on Cardiac Rehabilitation and Exercise Physiology. European Society of Cardiology (2003). Physical activity for primary and secondary prevention. Position paper of the Working Group on Cardiac Rehabilitation and Exercise Physiology of the European Society of Cardiology. European journal of cardiovascular prevention and rehabilitation: official journal of the European Society of Cardiology, Working Groups on
Epidemiology $\mathcal{E}$ Prevention and Cardiac Rehabilitation and Exercise Physiology, 10(5), 319327.

Golubic, R.E., K Wijndaele, R. L., Khaw, KT., Wareham, KT., \& Brage S. (2012). Rate of weight gain predicts change in physical activity levels: a longitudinal analysis of the EPIC-Norfolk cohort. Int J Obes, 37(3), 404-409.

Gormley, S.E., Swain, D.P., High, R., Spina, R.J., Dowling, E.A., Kotipalli, U.S., \& Gandrakota, R. (2008). Effect of Intensity of Aerobic Training on VO2max. Med Sci Sports Exerc, 40(7), 1336-43.

Gossard, D., Haskell, W.L., Taylor, C.B., Mueller, J.K., Rogers, F., Chandler, M., Ahn, D.K., Miller, N.H. \& DeBusk, R. (1986). Effects of low and high-intensity home-based exercise training on functional capacity in healthy middle-aged men. Am J Cardiol, 57 (6), 446-449.

Grant, S., Corbett, K., Davies, C., Aichison, T., Mutrie, N., \& Byrne, J. (2002). A comparison of physiological responses and rating of perceived exertion in two modes of aerobic exercise in men and women over 50 years of age. Br J Sports Med, 36(4), 276-281.

Gregg, E.W., Gerzoff, R.B., Caspersen, C.J., Williamson, D.F., \& Vankat Narayvan, K.M. (2003). Relationship of walking to mortality among US adults with diabetes. Arch Intern Med, 163, 1440-1447.

Gutin, B., Barbeau, P., Owens, S., Lemmon, C.R., Bauman, M., Allison, J., Kang, H.S., \& Litaker, M.S. (2002). Effects of exercise intensity on cardiovascular fitness, total body composition, and visceral adiposity of obese adolescents. Am J Clin Nutr, 75(5), 818-826.

Hartaigh, B.O., Gill, T.M., Shah, I., Hughes, A.D., Deanfield, J.E., Kuh, D., \& Hardy, R. (2014). Association between resting heart rate across the life course and all-cause mortality: Longitudinal findings from the Medical Research Council (MRC) National Survey of Health and Development (NSHD). J Epidemiol Community Health, 68(9), 883-889.

Haskell, W.L., Lee, I.M., Pate, R.R., Powell, K.E., Blair, S.N., Franklin, B.A. Macera, C.A., Heath, G.W., Thompson, P.D., \& Bauman, A. (2007). Physical activity and public health: updated recommendation for adults from the American College of Sports Medicine and the American 
Heart Association. Med Sci Sports Exerc, 39(8), 1423-1434.

Heath, G.W., Hagberg, J.M., Ehsani, A.A., \& Holloszy, J.O. (1981). A physiological comparison of young and older endurance athletes. J Appl Physiol, 51, 634-640.

Higginbotham, M.B., Morris, K.G., Williams, R.S., McHale, P.A., Coleman, R.E., \& Cobb, F.R. (1986) Regulation of stroke volume during submaximal and maximal upright exercise in normal man. Circ Res, 58(2), 281-291.

Hsiao, E.T. \& Thayer, R.E. (1998). Exercising for mood regulation: the importance of experience. Pers Individ Dif, 24(6), 829-836.

Hu, F.B., Stampfer, M.J., Colditz, G.A., Ascherio, A., Rexrode, K.M., Willett, W.C. \& Manson, J.E. (2000). Physical activity and risk of stroke in women. JAMA, 283(22), 2961-2967.

Huang, G., Gibson, C.A., Tran, Z.V., \& Osness, W.H. (2005). Controlled endurance exercise training and $\mathrm{VO}_{2}$ max changes in older adults: a metaanalysis. Prev Cardiol, 217-225.

Huang, G., Shi, X., Davis-Brezette, J.A., \& Osness, W.H. (2005). Resting heart rate changes after endurance training in older adults: a metaanalysis. Med Sci Sports Exerc, 37(8), 1381-1386.

Jakovljevic, D.G. (2018). Physical activity and cardiovascular aging: physiological and molecular insights. Exp Gerontol, 109, 67-74.

James, P.A., Oparil, S., Carter, B.L., Cushman, W.H., Dennison-Himmelfarb, C., Handler, J., Lackland, T.D., LeFevre, M.L., MacKenzie, T.D., Ogedegbe, O., Smith, S.C., Svetke, L.P., Taler, S.J., Townsend, R.R., Wright, J.T., Narva, A.S., \& Ortiz, E. (2014). 2014 evidence-based guideline for the management of high blood pressure in adults: report from the panel members appointed to the Eighth Joint National Committee (JNC 8). JAMA, 311(5), 507-520.

Kalyani, M.N., Ebadi, A., Mehri, S.N., \& Motamedi, M.H.K. (2007). Survey the effect of aerobic exercise on aerobic capacity in patients with coronary artery disease (CAD). Pak J Med Sci, 23(5), 665-670.

Kang, H.S., Gutin, B., Barbeau, P., Owens, S., Lemmon, C.R., Allison, J., Litaker, M.S., \& Le, NA. (2002). Physical training improves insulin resistance syndrome markers in obese adolescents. Med Sci Sports Exerc, 34(12), 19201927.

Kelley, G.A. \& Kelley, K.S. (2013). Effects of exercise in the treatment of overweight and obese children and adolescents: a systematic review of meta-analyses. J Obes, 10.

Kingwell, B.A., \& Jennings, G.L. (1993). Effects of walking and other exercise programs upon blood pressure in normal subjects. Med J Aust, 158(4), 234-238.

Kostić, R. \& Zagorc, M. (2005). A comparison of the changes in cardio-vascular fitness from two models of women's aerobic training. FU Phys Ed Sport, 3(1), 45-57.

Kuper, K. (1971). Aerobik. Beograd: Jugoslovenski Savez Organizacija Za Fizičku Kultu.

Lee, H.C., Lee, M.L., \& Kim, S.R. (2015). Effect of exercise performance by elderly women on balance ability and muscle function. J Phys Ther Sci, 27(4), 989-992.

Levy, W.C., Cerqueira, M.D., Harp, G.D. Johannessen, K.A., Abrass, I.B., Schwartz, R.S., \& Stratton, J.R. (1998). Effect of endurance exercise training on heart rate variability at rest in healthy young and older men. Am J Card, 82(10), 1236-1241.

Liu, F., Wang, W., \& Zhuang, G. (2018). Different associations of sufficient and vigorous physical activity with BMI in Northwest China. Sci Rep 8, 13120.

Lynch, J., Helmrich, S.P., Lakka, T.A., Kaplan, G.A., Cohen, R.D., Salonen, R., \& Salonen, J.T. (1996). Moderately intense physical activities and high levels of cardiorespiratory fitness reduce the risk of non-insulin-dependent diabetes mellitus in middle-aged men. Arch Intern Med, 156, 13071314.

Nystoriak, M.A., Bhatnagar, A. (2018). Cardiovascular effects and benefits of exercise. Front Cardiovasc Med, 5, 135.

McGinnis, J.M. \& Foege, W.H. (1993). Actual causes of death in the United States. JAMA, 270(18), 2207-2212.

Members, A.F., Mancia, G., Fagard, R., Narkiewicz, K., Redon, J., Zanchetti, A., Bohm, \& M. (2013). 2013 ESH/ESC Guidelines for the management of 
arterial hypertension. Europen Heart Journal, 34, 2159-2219.

Mendis, S. (2014). Global status report on noncommunicable diseases. World Health Organization, 2014.

Myers, J., Prakash, M., Froelicher, V., Do, D., Partngton, S., \& Atwood, J.E. (2002). Exercise capacity and mortality among men referred for exercise testing. $N$ Engl J Med, 346(11), 793-801.

Nottin, S., Vinet, A., Stecken, F., N'Guyen, L.D., Ounissi, F., Lecoq, A.M., \& Obert, P. (2002). Central and peripheral cardiovascular adaptations to exercise in endurance-trained children. Acta Physiol Scand, 175(2), 85-92.

Nystoriak, M.A., \& Bhatnagar, A. (2018). Cardiovascular effects and benefits of exercise. Front Cardiovasc Med, 5, 135.

O'Donovan, G., Owen, A., Bird, S.R., Kearney, E.M., Nevill, A,M., Jones, D.W., \& May, K.W. (2005). Changes in cardiorespiratory fitness and coronary heart disease risk factors following 24 wk of moderate- or high-intensity exercise of equal energy cost. J Appl Physiol, 98(5), 1619-1625.

Osei-Tutu, K.B. \& Campagna, P.D. (2005). The effects of short- vs. long-bout exercise on mood, $\mathrm{VO}_{2}$ max, and percent body fat. Prev Med, 40(1), 92-98.

Pantelić, S., Kostić, R., Mikalački, M., Đurašković, R., Čokorilo, N., Mladenović, I. (2007). The effects of a recreational aerobic exercise model on the functional abilities of women. FU Phys Ed Sport, 5(1), 19-35.

Pearson, T.A., Blair, S.N., Daniels, S.R., Eckel, R.H., Fair, J.M., Fortmann, S.P., Franklin, B.A., Goldstein, L.B., Greenland, P., Grundy, S.M., Hong, Y., Milller, N.H., Lauer, R.M., Ockene, I.S., Sacco, R.L., Sallis, J.F., Jr, S.C.S., Stone, N.J., \& Taubert, K.A. (2002). AHA guidelines for primary prevention of cardiovascular disease and stroke: 2002 update: consensus panel guide to comprehensive risk reduction for adult patients without coronary or other atherosclerotic vascular diseases. Circulation, 106 (3), 388-391.

Pescatello, L.S. \& Kulikowich, J.M. (2001). The aftereffects of dynamic exercise on ambulatory blood pressure. Med Sci Sports Exerc, 33(11), 1855-1886.
Pescatello, L.S., Blanchard, B.E., Tsongalis, G.J., O'Connell, A.A., Gordish-Dressman, H., Maresh, C.M., \& Thompson, P.D. (2008). et al. A comparison of the genetic and clinical profile of men that respond and do not respond to the immediate antihypertensive effects of aerobic exercise. Appl Clin Genet, 1, 7.

Pescatello, L.S., Franklin, B.A., Fagard, R., Farquhar, W.B., Kelley, G.A., \& Ray, C.A. (2004). Exercise and Hypertension. Med Sci Sports Exerc, 36(3), 533-553.

Petrovic-Oggiano, G., Damjanov, V., Gurinovic, M. \& Glibetić, M. (2010). Fizička aktivnost u prevenciji i redukciji kardiovaskularnog rizika. Medicinski Pregled, 63(3-4), 200-207.

Pilch, W., Tyka, A., Cebula, A., Śliwicka, E., Pilaczyńska-Szcześniak, L., \& Tyka, A. (2017). Effects of a 6-week nordic walking training on changes in 25(oh)d blood concentration in women aged over. J Sports Med Phys Fitness, 57(12), 124-129.

Pimentel, A.E., Gentile, C.L., Tanaka, H., Seals, D.R., \& Gates, P.E. (2003). Greater rate of decline in maximal aerobic capacity with age in endurancetrained than in sedentary men. J Appl Physiol, 94, 2406-2413.

Pinckard, K., Baskin, K.K., \& Stanford, K.I. (2019) Effects of exercise to improve cardiovascular health. Front Cardiovasc Med, 6, 69.

Pontes, F.L., Jr, B.R.F., Moraes, M.R., Navarro, F., Casarini, D.E., Pesquero, J.B., Araujo, R.C. \& Picarro, I.C. (2008). Kallikrein kinin system activation in post-exercise hypotension in water running of hypertensive volunteers. Int Immunopharmacol, 8(2), 261-266.

Rennie, K.L., Hemingway, H., Kumari, M., Brunner, E., Malik, M., \& Marmot, M. (2003). Effects of moderate and vigorous physical activity on heart rate variability in a British study of civil servants. Am J Epidemiol, 158(2), 135-143.

Rezaimanesh, D. \& Amiri-Farsani, P. (2011). The effect of a six weeks aerobic and anaerobic intermittent swimming on $\mathrm{VO}_{2}$ max and some lung volumes and capacities in student athletes. Procedia Soc Behav Sci, 15, 2054-2057.

Rossi, A., Dikareva, A., Bacon, S.L., \& Daskalopoulou, S.S. (2012). The impact of physical activity on mortality in patients with 
high blood pressure: a systematic review. J Hypertens, 30(7), 1277-1288.

Savage, M.P., Petratis, M.M., Thomson, W.H., Berg, K., Smith, J.L., \& Sady, S.P. (1986). Exercise training effects on serum lipids of prepubescent boys and adult men. Med Sci Sports Exerc, 18(2), 197-204.

Schuit, A., van Amelsvoort, L., Verheij, T., Rijneke, R., Maan, A., Swenne, C. \& Schouten, E. (1999). Exercise training and heart rate variability in older people. Med Sci Sports Exerc, 31(6), 816-821.

Schuit, A.J., van Amelsvoort, L.G., Verheij, T.C., Rijneke, R.D., Maan, A.C. Swenne, C., \& Schouten, E. (1999) Exercise training and heart rate variability in older people. Med Sci Sports Exerc, 31(6), 816-821.

Shim, A., Westcott, W., Smith, A., \& Drum, S. (2010). Effects of resting metabolic rate and resting $\mathrm{VO}_{2}$ based on an 8 week strength training program on senior adults. J Sci Med Sport, 12, 163.

Shin, K., Minamitani, H, Onishi, S. Yamazaki, H., Lee, M. (1997). Autonomic differences between athletes and nonathletes: spectral analysis approach. Med Sci Sports Exerc, 29(11), 1482-1490.

Thomsen, D., \& Ballor, D. (1991). Physiological responses during aerobic dance of individuals grouped by aerobic capacity and dance experience. Res Q Exerc Sport, 62(1), 68-72.
Warburton, D.E., Gledhill, N., \& Quinney, A. (2001). The effects of changes in musculoskeletal fitness on health. J Appl Physiol, 26, 161-216.

Wilmore, J.H. \& Costill, D.L. (2005). Physiology of sport and exercise. Champaign: Human Kinetics.

Wilmore, J.H., \& Costill, D.L. (1999). Physiology of sport and exercise. Second Edition, Champaign, IL: Human Kinetics.

World Health Organization. (2019). Global strategy on diet, physical activity and health.

World Health Organization (2019). Physical activity and older adults.

Yataco, A.R., Fleisher, L.A., \& Katze, L.I. (1997). Heart rate variability and cardiovascular fitness in senior athletes. Am J Cardiol, 80, 1389-1391.

Yong, MH., Shin JI., Yang DJ., \& Yang, YA. (2014). Comparison of physical fitness status between middle-aged and elderly male laborers according to lifestyle behaviors. J Phys Ther Sci, 26(12), 1965-1969.

Zheng, G., Li, S., Huang, M., Liu, F., Tao, J., Chen, L. (2015). The effect of Tai Chi training on cardiorespiratory fitness in healthy adults: a systematic review and meta- analysis. PLoS One, 10(2), e0117360. 